\title{
O QUE APRENDI COM O PEAD: COMO EXPLICO O SUCESSO DO CURSO
}

\author{
Tania Beatriz Iwaszko Marques, FACED - UFRGS \\ taniabimarques@bol.com.br
}

RESUMO: Por meio deste texto analiso o meu próprio percurso como docente do Curso de Licenciatura em Pedagogia na modalidade a distância da UFRGS, especialmente minha atuação no polo de São Leopoldo. Recolhendo minhas percepções a respeito das transformações que ocorreram no curso, reflito, embasada na Epistemologia Genética de Jean Piaget (1983), sobre as razões pelas quais acredito que o curso conseguiu ser bem sucedido, inclusive obtendo uma taxa de evasão inferior a cursos na modalidade presencial. Desta forma, procuro traçar paralelos entre o meu percurso e o do curso, identificando minhas próprias aprendizagens e os fatores que contribuíram o para o sucesso do curso.

PALAVRAS-CHAVE: PEAD; aprendizagem; educação a distância; epistemologia genética; interacionismo/construtivismo.

\section{WHAT I LEARNED WITH PEAD: MY EXPLANATION FOR THE SUCCESS OF THE COURSE}

ABSTRACT: Through this article I analyze my own journey as a teacher in pedagogy in distance in UFRGS, especially my work on the pole of São Leopoldo. Gathering my perceptions about the transformation that occurred in the course, I reflect, based on Jean Piaget's (1983) Genetic Epistemology, on the reasons why I believe that the course could be successful, even getting a dropout rate below courses in attendance. Thus, I try to draw parallels between my journey and the history of the course, identifying my own learning and the factors that contributed to the success of the course.

KEYWORDS: PEAD; learning; distance education; genetic epistemology; interactionism / constructivism. 
É com crase ou sem crase? Educação à distância ou educação a distância? Muitas vezes me fiz essa pergunta e a escutei inúmeras vezes. E o que tem isso a ver com o $\mathrm{PEAD}^{1}$ ? Trata-se de um detalhe, mas um pequeno detalhe pode algumas vezes fazer muita diferença. Neste texto, quero chamar a atenção sobre o cuidado com os detalhes, o que, do meu ponto de vista, fez toda a diferença para o sucesso do curso.

Este texto traz a leitura de quem, ao longo do curso, esteve perto o suficiente para poder observar o que estava acontecendo, mas, ao mesmo tempo, longe para manter a capacidade de observação.

Sou professora universitária desde o ano de 1986 e antes disso tinha sido monitora durante quatro dos cinco anos de minha graduação em psicologia ${ }^{2}$. Na minha experiência em magistério de nível superior, trabalhei com diferentes cursos, seja na graduação ou na pós-graduação, seja na modalidade presencial ou na modalidade a distância.

Tenho pelo PEAD um carinho especial, porque com ele também aprendi muitas coisas e acredito que o relato dessas aprendizagens possa ser útil para outras pessoas. Minha experiência com o PEAD está ligada, sobretudo, ao polo de São Leopoldo ${ }^{3}$. Tive, em um único semestre, mais precisamente no quinto, uma pequena experiência com o polo de Sapiranga, da qual me lembro com muito carinho, porém, sequer cheguei a trabalhar com todo o grupo, pois orientei uma pequena parte da turma nos Projetos de aprendizagem em ambientes virtuais.

Como característica pessoal, estou sempre em busca de novas aprendizagens. Por isso, quando, no ano de 2005, nunca tendo trabalhado com educação a distância, recebi o convite para participar da construção de materiais para o curso, não hesitei sequer por um instante. Aceitei o desafio na hora, pois tinha interesse em entender um pouco o que era essa educação a distância da qual tanto ouvia falar, principalmente mal, mas que não conhecia. Sim, ainda hoje se ouve falar mal da educação a distância, e acredito que, em parte, por desconhecimento e, em parte, por experiências realmente infelizes.

Assim como o ensino presencial pode ser de boa ou de má qualidade, a mesma coisa acontece com a educação a distância. A educação não é boa porque é presencial ou a distância, mas, do meu ponto de vista de estudiosa da aprendizagem humana, entre outras razões, pela forma como ocorre essa educação. Tanto uma modalidade quanto outra pode estar baseada em diferentes modelos epistemológicos e isso, embora não seja o único, consiste em um elemento importante na análise do sucesso do curso.

Quando fui chamada para participar do PEAD, juntamente com as colegas, fiz um curso de formação e partimos para a construção dos materiais, antecipando disciplinas que aconteceriam dali a alguns semestres ou mesmo anos. Asseguro que foi uma experiência proveitosa. Aprendi muitas coisas nessa formação e várias delas efetivamente utilizei.

Aprender a criar materiais bonitos e interessantes é muito bom, mas a beleza e o dinamismo dos materiais não garante um ensino que promova a aprendizagem. Essa armadilha é comum, conforme já indicava Piaget (1976, p.80):

[...] uma pedagogia fundada na imagem, ainda quando enriquecida pelo dinamismo aparente do filme, permanece inadequada para a formação do construtivismo operatório, porque a inteligência não se reduz às imagens de um filme [...] Mas existe um verbalismo da imagem, assim como existe um verbalismo da palavra e, confrontados com os métodos ativos, os métodos intuitivos apenas substituem [...] o verbalismo tradicional pelo verbalismo mais elegante e refinado. 
Piaget (1998, p. 235) já alertava para o fato de que "existe um verbalismo da imagem tão perigoso quanto o verbalismo da palavra”. O autor (1984, p.9) afirma que os métodos audiovisuais "podem levar a uma espécie de verbalismo da imagem quando se limitam a favorecer as associações sem conceder oportunidades para atividades autênticas”.

Mas, como era exigência para a aprovação do curso, os materiais tiveram que ser produzidos e o grupo da área de psicologia da educação, do qual faço parte, empenhouse nessa tarefa. Isso sem conhecer a turma, sem saber sua realidade, ignorando a sua experiência e, sobretudo, sem levar em conta o próprio processo de construção de conhecimento. Apesar de nossas boas intenções, era muito difícil promover "atividades autênticas” (PIAGET, 1984, p.9) nessas condições.

Em que modelo naquele momento estava baseada a organização de materiais? As tarefas, em grande parte, consistiam em ler textos e responder questões. Um modelo que não levava em conta as experiências e a atividade docente de cada aluna-professora. Ou seja, um modelo empirista que se baseia na ideia de passar o conteúdo e depois esperar que os alunos o repitam para mostrar que aprenderam.

Uma pedagogia baseada nessa crença considera que "o conhecimento pode ser transmitido para o aluno. [...] acredita no mito da transmissão do conhecimento - do conhecimento enquanto forma ou estrutura; não só enquanto conteúdo" (BECKER, 2001b, p. 16). Para o empirismo, o sujeito da aprendizagem é considerado "em cada novo nível, como tabula rasa" (BECKER, 2001a, p. 9), e, por isso, a aula pode estar pronta independente dos conhecimentos prévios do aluno e de seu processo de construção e nega a importância da ação para que a aprendizagem ocorra.

Mas chegou o momento de trabalho efetivo no curso. Minha primeira participação aconteceu no segundo semestre do curso ${ }^{4}$, ou seja, no primeiro semestre de 2007, quando fui designada para o polo de São Leopoldo. Quanta novidade! Para começar, grande parte dos materiais confeccionados tanto tempo antes tinham perdido o sentido e foi preciso reorganizar as aulas.

Como escreveu a comissão de formatura do Polo de São Leopoldo em sua mensagem aos colegas no convite: "Entramos no ROODA ${ }^{5}$ e tivemos que nos adaptar a ambientes nunca antes explorados: pbworks, blogs, fóruns, webfólio, ...” Para o grupo, novidades. Muitas alunas professoras ${ }^{6}$ nem sabiam usar o computador. Muitas não tinham acesso à internet. Para mim, novidades também, pois não sabia como fazer para que uma aula a distância superasse um modelo educacional de simples transmissão de informação. Afinal, o modelo mais comum de educação, seja presencial ou a distância, continua sendo o modelo de repasse de informações. Se é difícil superá-lo na modalidade presencial, me parecia mais difícil, ainda, na modalidade a distância.

Essa era minha principal dúvida, mas também era a batalha constante de toda a equipe coordenadora que, por meio das reuniões constantes, conseguiu avançar com o curso na direção da superação do modelo empirista, chegando ao modelo interacionista, que serviu como base para o curso, conforme o guia do professor (CARVALHO et al., 2006).

A Epistemologia Genética de Jean Piaget (1983), que dá sustentação teórica ao curso, está embasada em um modelo interacionista, e explica a gênese das estruturas cognitivas pela construção - daí construtivismo - mediante a interação radical entre sujeito e objeto. Para a perspectiva interacionista, "o conhecimento deve ser considerado como uma relação de interdependência entre o sujeito conhecedor e o objeto a ser conhecido, e não como a justaposição de duas entidades dissociáveis" (INHELDER et al., 1977, p. 17). Isto é, o conhecimento não se origina por pressão do 
meio - aprendizagem stricto sensu (empirismo) - ou por estruturas pré-determinadas (apriorismo).

Considero que um dos pontos favoráveis para o curso poder se aproximar, na prática, de um modelo pedagógico interacionista tenha sido a existência das reuniões constantes. Reuniões entre coordenação e professores do eixo ${ }^{7}$ em andamento para tentar dar uma unidade ao trabalho realizado, com o objetivo de efetivar um trabalho interdisciplinar. O curso adotou, desde seu planejamento, a terminologia interdisciplina e investiu para que, de fato, ocorresse um trabalho nessa direção. Houve várias reuniões preparatórias entre coordenação e o eixo que iria iniciar. Também ocorriam reuniões constantes entre docentes de mesma área dos diferentes polos para que fosse feito o planejamento do andamento das atividades.

Quanto aos materiais previamente organizados, como ser interacionista sem levar em conta, para a organização das próximas aulas, o que está sendo produzido pelo grupo? Houve reuniões constantes entre os professores e seus tutores ${ }^{8}$ para que se organizassem estratégias de operacionalização das atividades. Além disso, os tutores receberam formação ao longo de todo o curso. Sem dúvida nenhuma, o formato do PEAD, com a presença de seus tutores ao longo do curso, permitiu um acompanhamento detalhado da evolução de cada aluna-professora. Criaram-se laços importantes e foi possível construir uma história. Muitos professores participaram em alguns momentos do curso, mas os tutores acompanharam a história do grupo.

O mesmo com relação ao Seminário Integrador. Uma grande ideia: uma interdisciplina que se mantém ao longo do curso, com os mesmos professores, que acompanha todo o curso e que dá suporte às outras interdisciplinas que acontecem no semestre. O Seminário realmente cumpriu a função de integrar conteúdos e pessoas, sendo um elemento que, do meu ponto de vista, fez a diferença no sucesso do curso.

Quando cheguei ao curso, no seu segundo semestre, um dos desafios era encontrar o melhor formato de distribuição de carga horária. Várias interdisciplinas ao mesmo tempo ou poucas interdisciplinas concentradas em pouco tempo, sendo seguidas de outro grupo? Nesse momento, Aprendizagem e desenvolvimento sob o enfoque da psicologia I foi desenvolvida paralelamente com a Alfabetização. Com uma carga horária grande concentrada em pouco tempo, o formato didático não se mostrou muito bom e foi abandonado. Houve tentativas de realizar atividades conjuntas. Muito boa ideia. Mas como operacionalizá-la em uma plataforma de educação a distância?

Operacionalizar: essa passou a ser uma palavra que me acompanha na educação a distância e também na presencial. Como operacionalizar? Se a atividade é conjunta, as alunas professoras devem postá-las em qual local? Quem fica encarregado de avaliálas? Como transformar boas ideias em uma aula a ser realizada a distância?

Pode parecer óbvio, mas toda tarefa que é solicitada deve ser avaliada. Se isso não for feito de forma adequada e no tempo hábil, corre-se o risco de perda do interesse e também de criação de estratégias para burlar as tarefas. Portanto, surgem questões: Quem dará devoluções adequadas e no tempo adequado? Como explicar a atividade de forma que fique clara?

Para o envio de uma mensagem, detalhes se tornam significativos, como, por exemplo: se dirigir à turma ou à pessoa? Quem lê a mensagem é uma pessoa, na tela de seu computador, e não um grupo de pessoas. Usar o plural é um vício da aula presencial, pois se presume que se está sempre diante de um grupo.

Como ser a mais clara possível nas explicações? Quando se está na sala de aula e não se é clara na explicação de como será feita uma atividade, a resposta à pergunta de alguém serve à turma. Se a mensagem enviada à turma na educação a distância não for 
clara, isso significará uma enorme quantidade de mensagens de pessoas angustiadas com pedidos de explicação. É importante lembrar que cada turma iniciou com 80 pessoas. No caso de São Leopoldo, 79 alunas e o Marcelo.

Outro desafio consiste em maximizar o resultado do trabalho das alunas professoras e também dos tutores e docentes. Existem tipos de atividades que fazem as estudantes trabalhar muito. Elas postam o seu trabalho individualmente e só os professores e os tutores têm acesso a eles, o que dá muito trabalho para todos. Mas os efeitos pedagógicos podem ser pequenos, porque não se fica sabendo o que os outros pensaram. Não há discussão, não se aproveitam os comentários feitos para os outros. O trabalho, para quem tem que ler, é desgastante, além de ser uma luta constante contra o relógio. Aprende-se, assim, a usar ferramentas que possam dar maior retorno às alunas professoras, maximizando também o resultado do trabalho dos docentes e dos tutores. Espaços públicos em que o compartilhamento de comentários pode ser utilizado passam a ser privilegiados, tais como fóruns de discussões e pbworks ${ }^{9}$. As alunas professoras passam a ser exigidas para colaborar nas atividades das colegas e se tornam mais ativas no processo. Há mais exigência, mas se percebe uma maior satisfação na realização das atividades, pois elas passam a ter maior significado.

Isso traz consequências! Já existem pesquisas mostrando que alguns cursos a distância conseguem melhores resultados do que os presenciais na medida em que o aluno presencial pode estar apenas de corpo presente sem participação efetiva. O aluno da educação a distância precisa produzir textos e trabalhos. Ele acaba sendo mais exigido!

Outra diferença marcante: tudo o que se produz fica registrado. Na aula presencial, em uma discussão que pode ser muito interessante, não ficam registros. Na modalidade a distância, a discussão realizada por meio do fórum permanece como um registro que pode ser retomado a qualquer momento.

Além disso, a maravilha da aula assíncrona! Cada um pode otimizar o seu tempo. A legislação da educação a distância exige uma carga horária mínima de horas presenciais, e essas sempre foram gratificantes para mim, porque gosto desse contato presencial. Como o tempo era precioso, ele sempre foi aproveitado ao máximo. Foi necessário aprender a otimizar os momentos de encontro e propor atividades que não poderiam ser realizadas a distância. Passar um power point? Passar um filme? Nem pensar. "As pessoas vêm de longe e têm pouco tempo, então precisa ser uma atividade que realmente valha a pena”. Essa é uma frase que ouvi muitas vezes.

E para concluir as reflexões sobre a primeira experiência no PEAD, retomo questões sobre a avaliação final. A avaliação final precisa ser presencial e a princípio eram realizadas provas. A prova de psicologia e de alfabetização foi realizada em conjunto, ou seja, tratava-se de uma única prova dissertativa envolvendo as duas interdisciplinas. Surgiram, naquele momento, importantes dilemas sobre a avaliação, pois cada aluna professora só poderia ser reprovada em uma única disciplina por semestre, caso contrário perderia sua vaga no curso. O dilema consistia no fato de que todas já atuavam em sala de aula e, caso fossem reprovadas em mais de uma disciplina, seriam afastadas do curso, perdendo sua vaga, porém, continuariam com sua atuação docente. Como lidar com o dilema? Fazer avançar, sabendo que algumas pessoas estavam com muitas dificuldades ou tirar sua oportunidade de estudos? O dilema foi grande, mas a aposta de mantê-las, reconhecendo suas dificuldades, mostrou-se correta, pois, no final do curso, foi possível ver o grande avanço, que não teriam tido, certamente, se tivessem sido afastadas do curso. 
Após esse primeiro contato com o PEAD, no seu segundo semestre de funcionamento, retornei no quinto semestre com Psicologia da vida adulta. Foi uma alegria imensa, pois tive uma bela surpresa: aconteceu um salto de qualidade enorme na turma. Não cansei de dizer isso em todas as reuniões das quais participava. Repeti isso, como paraninfa, para a turma de São Leopoldo, por ocasião de sua formatura. A proposta de trabalho teve como elemento principal a realização de um trabalho em grupo envolvendo temática sobre a vida adulta. Foram utilizados diferentes recursos, resultando em trabalhos teóricos ou em pesquisa de campo, com coleta de dados mediante entrevistas, questionários ou enquetes. Os trabalhos foram feitos em diversas versões, sendo apresentados no ROODA ou no pbworks. No último dia de aula ocorreu o encontro presencial para a apresentação dos trabalhos. Todos se lamentaram pelo fato de o tempo ser tão pouco, pois havia muito a mostrar. O que isso significa? Muita aprendizagem realizada e muitas aprendizagens possíveis. A organização da interdisciplina foi baseada na ideia piagetiana de que se aprende na ação.

Compartilho com Mirna Spritzer (2000, p.35) a ideia de que é necessário: "Deixar de tratar o ensino universitário [...] apenas como repasse de conhecimento [...]. Ensino é produção de conhecimento e também possibilidade de transformação para ambos, professor e aluno. Enquanto ensina, o professor reconstrói o conhecimento nessa ação". Concordo com Becker (2001a, p.20) quando afirma que "É a ação do sujeito que constrói este novo e fascinante mundo: o mundo do conhecimento - como forma e como conteúdo".

No final do semestre outra surpresa. A forma de avaliação final não é mais feita por meio de uma prova, mas por meio do workshop de apresentação do portfólio de aprendizagem, que consiste em uma atividade envolvendo todas as interdisciplinas do semestre. É produzido um material escrito que é avaliado e ao qual são feitas sugestões e, posteriormente, apresentado em bancas, em grupos de dez alunas professoras, com a avaliação realizada entre pares e por um dos docentes, com o apoio dos tutores.

No sexto semestre, volto com o Desenvolvimento e aprendizagem sob o enfoque da psicologia 2. A turma fez ótimas discussões! Estavam realmente pensando a educação e a sua sala de aula. Cada tema trabalhado foi proposto a partir das experiências em sala de aula como educadoras, com o propósito de pensar teoricamente a sua experiência docente, a partir da Epistemologia Genética. Tentamos trabalhar a teoria de Piaget a partir de uma proposta pedagógica baseada em seus próprios pressupostos teóricos. Diferentemente do que diz o senso comum, para quem a aprendizagem é um processo passivo, Piaget (1976, p.37) insiste na ideia de que conhecimento é ação, transformação e estabelecimento de relações, pois, "conhecer um objeto é agir sobre ele e transformá-lo, aprendendo os mecanismos dessa transformação, vinculados com as ações transformadoras. Conhecer é, pois, assimilar o real às estruturas de transformações [...]”.

No sétimo semestre, que pena, nenhuma interdisciplina. Fico com uma vontade imensa de retornar. E que alegria quando, no oitavo semestre, fico sabendo que posso voltar para orientar os estágios. Que desafio realizar as visitas às escolas! Denise ${ }^{10}$ dirigindo e eu guiando-a com os mapas. Quantas coisas aprendemos! Ao visitarmos as escolas, pudemos constatar o quanto este curso, que nasceu com o objetivo de formar professores em exercício, teve impacto não apenas na vida dessas alunas, mas na comunidade escolar na qual se inserem. Isso foi possível sentir pela forma como fomos recebidas por todos os profissionais das escolas. Ouvimos depoimentos espontâneos sobre os ganhos com o curso. 
No nono semestre mais um desafio. A orientação dos trabalhos de conclusão. Fiquei com um grupo de doze orientandas, mais o Marcelo. Nesse momento, a ansiedade cresceu no grupo: será possível concluir o trabalho com qualidade dentro do prazo? Reaparece a questão do plágio, que foi trabalhada ao longo do curso, mas que agora se torna mais intensa. Conforme Gallego ${ }^{11}$ (2009, p. 5), que se debruçou sobre esse tema:

Ao longo do curso se observou que o conceito de autoria foi se construindo de modo mais efetivo pelos alunos. No princípio os casos de cópias de trabalhos de outros autores, sem as devidas referências, era algo comum. Com o tempo, muitos alunos passaram a demonstrar uma efetiva preocupação com a questão, nos dois sentidos. Ou seja, preocupam-se com as referências em seus trabalhos, com procurar criar algo verdadeiramente seu, assim como passam a buscar que a autoria de seus textos seja respeitada.

Chega o dia da apresentação. Antes, ansiedade pura. Após, alívio, já que as apresentações foram um sucesso.

Um rico processo. Pensar sobre ele constitui-se em uma verdadeira formação também para mim. Acho que poderia, eu também, receber um certificado pelas aprendizagens que realizei. Considerei o fato de ser escolhida como paraninfa da turma de São Leopoldo uma forma de sinalizar que esta minha aprendizagem mereceria uma colação de grau.

Foi uma honra imensa ser a paraninfa da primeira turma de curso de Graduação em Pedagogia Licenciatura da Faculdade de Educação da UFRGS na modalidade a distância. Aliás, a primeira colação de grau ${ }^{12}$ de um curso de graduação na modalidade a distância na UFRGS! Foi um momento especial não só para as pessoas envolvidas, mas também porque marcamos um momento histórico da Universidade Federal do Rio Grande do Sul. E tudo isso com uma baixíssima taxa de evasão, inclusive na comparação com os cursos na modalidade presencial.

Para aprender tanta coisa, contei com o carinho da turma e com a ajuda de queridas tutoras. Depois de ingressar no PEAD, trabalhei em outros cursos a distância. Mas este será sempre especial, não só por ser o primeiro, mas também por ter acompanhado a turma de forma intensa, em diferentes momentos ao longo do percurso. O percurso da turma foi também o meu percurso. O crescimento da turma foi também o meu crescimento. Por isso, agradeço à coordenação do curso que me permitiu essa grande experiência e à turma pela possibilidade de ter vivido essa experiência.

Amo ser professora. Educar, para muitos, é apenas questão de resistência física ou de amor. Educar é um ato de amor, como diria Paulo Freire (1983), mas também é um ato profissional. Ou melhor, para ser um ato de amor exige uma formação séria e competente como a oferecida por este curso de Graduação em Pedagogia modalidade a distância da Faculdade de Educação da UFRGS.

Por causa de um mecanismo chamado por Piaget (1983) de inconsciente cognitivo, temos a sensação de que sempre soubemos aquilo que sabemos. Se sempre soubemos, não nos damos conta de como era o nosso raciocínio antes de termos aprendido algo. Temos posse desse processo quando o estudamos porque, caso contrário, não nos lembramos dele. Ao nos lembrarmos do nosso raciocínio de quando criança, nós o reformulamos com base no raciocínio de hoje. Por isso, temos a sensação de que se dissermos algo para outra pessoa ela automaticamente o entenderá, porque tendemos a tratar o outro como se tivesse a mesma capacidade de raciocínio que nós, já que não nos lembramos do raciocínio que tínhamos antes de raciocinarmos da forma 
como o fazemos atualmente. Por isso, é tão necessária uma formação especial para ser educador.

Se estamos apaixonados por aquilo que fazemos, acabamos contagiando aqueles que nos cercam. Uma pesquisa diz que o que faz os alunos acharem seus professores e professoras legais é o fato de estarem contentes por estar com eles, é o estar contentes naquele momento em que entram na sala de aula (GARCIA, 1999). O que faz a diferença é estarem apaixonados por aquilo que fazem.

Creio que a educação é um ato político quando se aprende a reconhecer a necessidade do outro e a respeitá-la, sem por isso ignorar e passar por cima das próprias necessidades. Num momento em que se fala de inclusão, nos mais diferentes sentidos e circunstâncias, lembro que o termo incluir tem como um de seus significados compreender. Para incluir é necessário compreender. Para incluir é necessário respeitar e para respeitar é necessário conhecer as semelhanças e as diferenças, é sair do seu próprio lugar, sem abrir mão das características próprias. Aí está o cerne da democracia, o respeito mútuo. $\mathrm{O}$ respeito mútuo significa aceitar que os outros pensam de forma diferente do que se pensa e trabalhar com esses diversos pontos de vista, sem impor aos outros a própria maneira de pensar e sem perder a própria identidade.

É difícil medir a importância do trabalho do educador porque seu papel não é apenas passar informações. Ele serve de modelo para pessoas que estão num processo de construção de valores, de sua noção de moral, e aprendendo a se relacionar com o mundo e com o outro.

O respeito que as crianças recebem de suas educadoras será o respeito que aprenderão a levar por toda a sua vida. O respeito se constrói na medida em que se é respeitado. Por isso, a cada dia penso que, se quero ajudar a formar profissionais e, mais que tudo, cidadãos, devo respeitar e, com meu exemplo, ensinar que respeitem.

Educar, muito além de passar conteúdos, é também cuidar. E cuidar vai muito além de fazer o que eu quero. É dar aquilo que o outro necessita, e aquilo que o outro tem condições de aproveitar.

Concluí minha tese de doutorado afirmando: "O professor precisa pensar no aluno a partir do aluno, e não a partir dele próprio, para ajudar a construir o adulto capaz de conquistar, por si só, a beleza e a verdade do seu tempo” (MARQUES, 2005, p.254). Concluo, agora, dizendo que não existe alegria maior para quem educa do que ver uma pessoa aprendendo, tornando-se autônoma, construindo seus próprios caminhos.

\section{Notas do Texto}

\footnotetext{
${ }^{1}$ Curso de Licenciatura em Pedagogia na Modalidade a Distância da Universidade Federal do Rio Grande do Sul.

${ }^{2}$ Graduação em Psicologia na UFRGS de 1979 a 1983.

${ }^{3}$ O curso ocorreu mediante convênio com cinco prefeituras do estado do Rio Grande do Sul: São Leopoldo, Três Cachoeiras, Sapiranga, Gravataí e Alvorada.

${ }^{4}$ O curso iniciou no segundo semestre de 2006, com a oferta de 80 vagas para cada um dos cinco polos. Contudo, como algumas vagas não foram preenchidas, houve um novo ingresso em 2007/1.

${ }^{5}$ Rede cOOperativa De Aprendizagem - Ambiente virtual oficial utilizado pelo curso.

${ }^{6}$ Designação utilizada para os estudantes do curso já que necessariamente atuavam como docentes e eram, na sua quase totalidade, do sexo feminino.

${ }^{7}$ Designação dada ao conjunto de interdisciplinas de cada um dos semestres.
} 


\footnotetext{
${ }^{8}$ Cada professor contava com um ou dois tutores de sede, dando apoio no conteúdo, enquanto os tutores de polo davam assessoria no polo. Para uma descrição detalhadas das funções dos tutores, ver Carvalho, Nevado e Bordas (2006b).

${ }^{9}$ Segundo a Wikipédia, “O PBworks (antes conhecido por PBwiki) é uma ferramenta eletrônica comercial para construção de páginas web de fácil manejo e uso por usuários leigos. Ela permite que múltiplos usuários editem e alterem seu conteúdo através de um sistema de múltiplas autenticações simultâneas.”

10 Denise Severo, mestre em Educação, que me acompanhou, como tutora, em todas as minhas participações no curso.

${ }^{11}$ Em seu trabalho de conclusão do Curso de Especialização em Tutoria em Educação a Distância.

${ }^{12}$ A colação de grau ocorreu no Salão de Atos da UFRGS no dia 12 de janeiro de 2011.
}

\section{Referências bilbiográficas}

BECKER, Fernando. A epistemologia do professor. O cotidiano da escola. 9ed. Petrópolis: Vozes, 2001a.

BECKER, Fernando. Educação e construção do conhecimento. Porto Alegre: Artmed, 2001b.

CARVALHO, Marie Jane Soares; NEVADO, Rosane Aragon de; BORDAS, Mérion Campos. Licenciatura em pedagogia à distância: anos iniciais do ensino fundamental - Guia do professor. Porto Alegre: PEAD/UFRGS, 2006a.

CARVALHO, Marie. Jane. Soares; NEVADO, Rosane. Aragon de; BORDAS, Mérion Campos. Licenciatura em pedagogia à distância: anos iniciais do ensino fundamental - Guia do tutor. Porto Alegre: PEAD/UFRGS, 2006b.

FREIRE, Paulo. Educação como prática da liberdade. $16^{a}$ ed. Rio de Janeiro: Paz e Terra, 1983.

GALLEGO, Andréa Bonetti. Moralidade e autoria na rede: possibilidades de desenvolvimento na educação a distância. Porto Alegre: UFRGS/FACED, 2009. Trabalho de conclusão de curso de especialização em tutoria em educação a distância.

GARCIA, Olgair Gomes. Impossível?!... eu adoro ser professora. Revista de Educação AEC. Paixão e educação. v.28, n110, jan./mar. 1999. Brasília: AEC, 1999.

MARQUES, Tania Beatriz Iwaszko. Do egocentrismo à descentração: a docência no ensino superior. Porto Alegre: UFRGS/FACED, 2005. Tese de doutorado.

PIAGET, Jean. Psicologia e pedagogia. 4ed. Rio de Janeiro: Forense, 1976.

PIAGET, Jean. Problemas de psicologia genética. São Paulo: Abril Cultural, 1983. 
PIAGET, Jean. Para onde vai a educação. 8.ed. Rio de Janeiro: José Olympio, 1984.

PIAGET, Jean. Sobre a pedagogia. Textos inéditos. São Paulo: Casa do Psicólogo, 1998.

SPRITZER, Mirna. O invisível feito visível: um estudo sobre a formação do ator na universidade. Porto Alegre: UFRGS/FACED, 2000. Dissertação de Mestrado. 